\title{
A qualitative study of health care providers' perceptions and experiences of patients bypassing primary healthcare facilities: a focus from Nigeria
}

\author{
Francis G Koce', Gurch Randhawa', Bertha Ochieng ${ }^{2}$ \\ 1 Institute for Health Research, University of Bedfordshire, Putteridge Bury Campus, Luton, UK, 2 Faculty of Health \& Life Sciences, De Montfort \\ University, Leicester, UK. \\ Keywords: nigeria, primary health care, health systems, health care seeking behaviour
}

https://doi.org/10.29392/001c.14138

\section{Journal of Global Health Reports}

Vol. 4, 2020

\section{Background}

The healthcare referral system is designed to ensure that patients receive the best care at the appropriate level, as well as improving access to different levels of care. However, approximately $60-90 \%$ of patients in Nigeria bypass their local primary level of care to seek healthcare outside of the community. This study is part of a larger mixed methods study that explored the patients' and healthcare providers' perceptions and experiences in order to understand the factors that influence a patient's decision to bypass the primary level of care to go to secondary and tertiary level facilities. In this study we present the perspectives of the healthcare providers and the factors that influence a patient's decision to self-refer, as well as their suggestions for how primary healthcare facilities can retain patients locally.

\section{Methods}

In-depth semi-structured interviews were conducted with eighteen healthcare providers comprising doctors, nurses, and community healthcare workers from primary and secondary healthcare facilities in Niger State, Nigeria. The interviews were tape recorded and subsequently transcribed. The analysis was carried out using the principles of framework analysis.

\section{Results}

The shortage of healthcare providers at local facilities was described as a key reason for patients to self-refer to secondary and tertiary care. Lack of basic equipment, inequitable distributions, and the inconsistent opening hours of the primary healthcare facilities were also considered to be influencing factors for bypassing the primary health facilities. In order to encourage the use of the primary healthcare facilities, some of the healthcare providers suggested ensuring that medical doctors were stationed within those facilities, and also suggested the need for collaboration between the different levels of care, as current services appeared fragmented.

\section{Conclusions}

Interventions such as employing the services of doctors (family physicians) and standardising the primary healthcare facilities in terms of distribution and availability of the basic facilities are needed to reduce the barriers associated with the bypass of the primary level of care in low cost economies. In addition, tangible policies that ensure the primary health facilities are well resourced should be enacted. The findings have implications for planning, practice, and policy in service delivery aimed at curtailing the bypass of the primary health care facilities.

Globally, healthcare delivery is arranged in a hierarchy of primary, secondary, tertiary, and/or quaternary levels. This hierarchy ensures that: the integrity of the different levels are maintained, with patients receiving the best care at an appropriate level; hospital facilities are used optimally and cost-effectively; patients in most need of specialist services are able to access them in an appropriate manner, and; primary health services are well utilised and not undermined. ${ }^{1,2}$ Despite the adoption of the Alma-Ata Declaration as the cornerstone of the Nigerian health system in 1987,3 healthcare delivery undertaken by Primary Health Care (PHC) facilities has struggled to gain relevance. Notwithstanding, the Nigerian healthcare system has witnessed several reforms since its independence in $1960 .{ }^{4}$ One 
of the defining eras was the introduction of the Basic Health Services Scheme (BHSS) during the third National Development Plan (NDP) (1975-80). ${ }^{5}$ This saw the introduction and spread of PHC facilities such as health posts, primary health clinics, and primary healthcare centres. ${ }^{6,7}$ The fourth NDP (1981-85) further witnessed the enactment of policies for the provision of a comprehensive healthcare system offering promotional, protective, restorative, and rehabilitative services. This led to the formulation and development of a national comprehensive healthcare scheme, where healthcare services were provided across three levels (primary, secondary, and tertiary health facilities). ${ }^{8}$ However, despite the provision of care in three tiers, the Nigerian healthcare referral system has continued to be a challenging area, with patients utilising the higher levels of care as they deem fit. 8,9

Some of the Nigerian healthcare indices have persistently remained poor, for example, the probability of dying at under-five as at 2016 was $120 / 1000$ live births, and the life expectancy was 55 for males and 56 for females. ${ }^{10}$ Also, the maternal mortality ratio of $917 / 100,000$ live birth is one of the highest in the world. ${ }^{11}$ Healthcare financing in another aspect the government have struggled to address whereby out of pocket expenditure accounted for $77.7 \%$ of the total expenditure in 2017. ${ }^{12}$ Other issues of concern that have and continue to impact on the healthcare system in Nigeria are inadequate incentives, inadequate health workforce, poor equipment and infrastructure. ${ }^{13}$ Despite these poor indices, the total expenditure on healthcare is about 3.76 per cent of the total Gross Domestic Product (GDP) of the country. ${ }^{14}$ This is contrary to the Abuja Declaration of 2001, which the Heads of State for African Union countries pledged to allocate at least $15 \%$ of their total annual government budgets to the health sector. ${ }^{15}$

The provision of functional PHC facilities remains imperative in any healthcare system; without this, the secondary and tertiary levels of care would be overwhelmed with cases that could be effectively dealt with at the PHC level. ${ }^{16}$ It is equally important that hospitals do not offer treatment that could be provided by the primary levels of care; if they did, it would become overloaded and they would be unable to provide proper support to the community. ${ }^{17}$ In tandem with this observation, findings show that approximately $60-90 \%$ of patients in Nigeria bypass the PHC facilities to go to the higher levels of care. ${ }^{18-20}$ As such, the secondary and tertiary facilities have become overcrowded with patients that could have been easily managed at the PHC facilities. 5,9

Notably, healthcare delivery differs from one setting to another. Thus, the problem concerning the bypass of primary to higher levels of care takes different forms based on the context. ${ }^{21}$ Attempts have been made to understand the factors that facilitate or impede the circumvention of primary level facilities to higher level facilities in different settings. Findings have shown that factors such as healthcare insurance, ${ }^{22,23}$ knowledge regarding the healthcare delivery system ${ }^{24-26}$ and access to healthcare facilities ${ }^{27-29}$ are all associated with patients seeking care at referral facilities. Additional factors identified include the availability of healthcare providers and equipment. ${ }^{30-32}$ However, studies exploring healthcare providers' perspectives on this subject have been sparse, and have mainly emanated from developed settings. ${ }^{33-35}$ Healthcare providers and patients remain important co-actors in shaping and modelling the healthcare delivery system. Accordingly, the perspectives of these co-actors are noted as driving the quality of care within the healthcare system. ${ }^{36}$ Therefore, this study aims to explore the perspectives of the healthcare providers and thus identify some of the factors that may influence a patient's decision to self-refer.

\section{METHODS}

The study protocol for this study was approved by the Institute for Health Research Ethics Committee at the University of Bedfordshire and the National Health Research Ethics Committee (NHREC) of Nigeria. Written informed consent was obtained from each participant. Participants were selected via a purposive sampling technique from the primary and secondary healthcare facilities in Niger state, Nigeria. Due to their potential knowledge regarding the referral processes and challenges involved, the target was to recruit healthcare providers who attended to patients at the public PHC facilities and secondary healthcare facilities. Therefore, participants included nurses and community health workers (CHWs) from the primary level facilities, as they are the principal care providers at that level. Doctors were recruited from the secondary healthcare facilities because they are mainly involved in carrying out consultations at the General Outpatient Department (GOPD). All participants were provided with participant information sheets before they consented to participate. A total of eighteen healthcare providers were interviewed, comprising six doctors from the secondary healthcare facilities, six CHWs, and six nurses from the PHC facilities (Table 1).

An in-depth semi-structured interview was employed for this study, ${ }^{37}$ the interviews were tape recorded, and the duration of the interviews ranged between 15 and 34 minutes. All the interviews took place on the premises of the different healthcare facilities during working hours (between 08:00 and 16:00). Participants were asked questions surrounding: the functions of the different levels of the Nigerian healthcare system (primary, secondary, and tertiary levels), the process involved when referring or receiving a patient from another facility (higher or lower), factors that may facilitate or serve as barriers to bypassing the PHC facilities, and probing for the roles of opening hours, waiting times, transport, fees, equipment, and healthcare providers if not mentioned. Questions were also related to suggestions for curbing the bypass of the PHC facilities. These questions took cognisance of findings from the literature and from the researcher's experiences. ${ }^{37}$ All interviews were transcribed by the researcher.

\section{DATA ANALYSIS}

Framework analysis was adopted for the analysis of the data using the five stages of the framework approach, including: 1) familiarisation with the data - the transcripts were read by all members of the research team; 2) identifying a thematic framework - themes were compared and discussed 
Table 1: Socio-demographic characteristics of participants (healthcare providers)

\begin{tabular}{|c|c|c|c|c|}
\hline Identification no. & Age & Gender ( $\mathrm{M}=$ male; $F=$ female) & Duration of practice & Facilities \\
\hline Doctor1 & 32 & M & 4 years & General Hospital Tafa \\
\hline Doctor2 & 37 & M & 7 years & General Hospital Tafa \\
\hline Doctor3 & 40 & $M$ & 8 years & General Hospital Lapai \\
\hline Doctor4 & 40 & $M$ & 7 years & General Hospital Lapai \\
\hline Doctor5 & 37 & M & 5 years & General Hospital Wushishi \\
\hline Doctor6 & 43 & $M$ & 6 years & General Hospital Wushishi \\
\hline Nurse1 & 35 & $\mathrm{~F}$ & 13 years & PHC Tafa \\
\hline Nurse2 & 44 & $\mathrm{~F}$ & 26 years & PHC Tafa \\
\hline Nurse3 & 30 & M & 8 years & PHC Lapai \\
\hline Nurse4 & 41 & M & 3 years & PHC Lapai \\
\hline Nurse5 & 55 & $\mathrm{~F}$ & 35 years & PHC Wushishi \\
\hline Nurse6 & 58 & M & 29 years & PHC Wushishi \\
\hline CHW1 & 33 & $\mathrm{~F}$ & 13 years & PHC Tafa \\
\hline CHW2 & 46 & $M$ & 25 years & PHC Tafa \\
\hline CHW3 & 35 & $M$ & 4 years & PHC Lapai \\
\hline CHW4 & 37 & $\mathrm{~F}$ & 15 years & PHC Lapai \\
\hline CHW5 & 51 & $M$ & 25 years & PHC Wushishi \\
\hline CHW6 & 40 & $\mathrm{~F}$ & 28 years & PHC Wushishi \\
\hline
\end{tabular}

among the research team and a consensus was reached; 3) indexing - the themes were subsequently applied to the textual form of all the transcribed data using the NVivo10 software; 4) charting - to aid with tracking the account of each participant's transcript, a spreadsheet was created where the Page $(\mathrm{P})$ and Line $(\mathrm{L})$ numbers depicting the quotes from each participant that fit within the identified themes were placed in the respective cells; 5) mapping and interpretation - finally, the charts were reviewed to make connections between and within participants, seeking explanations for the patterns of the data. ${ }^{38,39}$

\section{RESULTS}

The analysis of the transcripts revealed five themes that were related to: unmet expectations at the PHC facilities, lack of manpower and preference for doctors, lack of equipment or facilities, access to healthcare facilities, and government regulations (policies).

\section{UNMET EXPECTATIONS AT THE PHC FACILITIES}

It was generally perceived by the participants that patients have an expectation regarding their care at the PHC facilities, and if not met, this results in them seeking care at a higher-level facility.

"The patients want the best and sometimes when they go to primary health centres, they spend money, time and at the end they don't get what they want. Also, it's the issue of confidence in the primary health centres. From what people have heard, they prefer to say no, no I don't just want to gamble with my health, let me go

\section{| straight to where I will get the best.” Doctor4.}

They also talked about the poor relationship between the patients and healthcare providers. This was mainly highlighted by the healthcare providers within the PHC facilities (CHWs and nurses), who pointed out that when there is poor rapport between the healthcare providers and their patients, there is a tendency to seek care elsewhere.

"There are also relationship issues... it's funny to find
out that there is a health facility with a health worker,
but there is no good rapport between them [patients]
and the health worker. So, they can bypass and decide
to go to the bigger hospital." Nurse5.

Consequently, one of the participants felt that ensuring a good rapport between the healthcare providers and their patients is likely to encourage patients to utilise the PHC facilities. He explained how visiting patients at their homes, with patients having easy access to him, tends to strengthen their relationship and motivate the utilisation of the PHC facility where he works.

\section{LACK OF MANPOWER AND PREFERENCE FOR DOCTORS}

The idea that patients want to be seen by a 'doctor' was a common perception among the participants. This view cut across the different groups of healthcare providers (doctors, nurses, and CHWs) who were interviewed. Participants noted that the absence of medical doctors at the PHC facilities deters patients from presenting to those facilities, despite the availability of nurses and CHWs.

| 'We don't have a doctor here (PHC facility)... So that 
is one of the factors why they [patients] are bypassing this hospital, the primary healthcare to the secondary healthcare." Nurse3.

Aside from the lack of doctors in the PHC facilities, the general shortage of healthcare providers at these facilities was also highlighted as a deterrent to using them. Interestingly, some of the doctors spoke about the competencies of the healthcare providers providing care at the PHC facilities, who are primarily the nurses and CHWs. It was stated that patients likely feel uncomfortable receiving care from the CHWs, which might impact on their use.

\section{"Most people are not comfortable with community health extension workers attending to them. It's just a psychological problem... it's sad actually and unsafe, that's the truth." Doctor1.}

Some of the suggestions from participants regarding the above barriers included the need to have not only trained and qualified staff at the PHC facilities, but doctors especially. Specific reference was made to having National Youth Service Corps (NYSC) doctors who are referred to as 'corpers' (these are the fresh medical graduates who are posted for their one-year mandatory national service) available at the PHC facilities. This was viewed as a potential means to encourage patients to utilise the PHC facilities.

\begin{abstract}
"Primary healthcare should have at least a resident doctor, one that will be able to give the necessary obstetric care, which most of the PHCs are lacking... It's imperative that a doctor should be positioned there to assist." Doctor3.

"...a doctor is supposed to be attached to each health facility, like this primary health facility is supposed to have at least a corper attached to it. You know, if we have that, we will have more clients." Nurse6.
\end{abstract}

Participants also suggested the need for collaboration between the different levels of facilities, believing it would decrease the burden on the secondary level of care and also encourage the use of the PHC facilities.

\section{LACK OF EQUIPMENT OR FACILITIES}

The different cadres (doctors, CHWs, and nurses) of participants perceived that the absence of facilities or equipment such as those used for investigations and drugs at the primary level of care was possibly related to the patients' decisions to sidestep them.

\section{"Maybe they [patients] feel we don't have enough facil- ities... Can't you see? Like you can see now, this place is somehow shabby and rough. Some people look at the environment before they come in. Some people even come in and go out because they feel the place is not convenient for them." CHW1.}

Some of the participants (mainly the nurses and CHWs at the PHC facilities) voiced their displeasure regarding the level and state of equipment within their facilities.

"The environment scares people... The equipment too, if this place [PHC facility] operates at a good standard, people will not bypass us [PHC facilities] to the general hospital. The equipment we use are not sterilised; you understand. We use stove and jik to sterilise our instrument. We are supposed to have autoclave to do all those things. The environment, in short, we are not satisfied with the equipment in comparison to the general hospital." Nurse1.

To avoid circumventing the primary level of care, participants suggested the need to have different facilities in place within the PHC setting. The facilities suggested included renovation of the physical structure of the PHC facilities, availability of medications, and provision of investigation equipment.

\section{ACCESS TO THE HEALTHCARE FACILITY}

\section{AVAILABILITY OF PHC FACILITIES}

One of the participants noted that the locations of the PHC facilities are not prioritised, pointing out that some areas have multiple facilities whereas others lack any of these facilities, thus prompting self-referral. They also emphasised that it was the political office holder who sited these facilities without proper consultation, and only for political gain.

"Now if I take you to one of the wards (community), you will discover that one of the wards has more than the necessary health facility. One village has about three health facilities, just because they have the advantage of having political officers. Do you understand? Whereby around that village, there are other villages that need a dispensary but they don't have." CHW5.

\section{PROXIMITY OF PHC FACILITIES}

The proximity of a secondary healthcare facility to patients was also perceived as a reason that could prompt patients to self-refer, especially if their closest PHC facilities are miles away from where they reside.

"Some could be due to the proximity to them, you know. I can't be going to the primary health centre that is like 7 kilometres from me and I have a secondary health centre that is 2 kilometres away from me." Doctor4.

\section{AVAILABILITY OF SERVICES}

The healthcare providers spoke about the role of the opening and closing hours of the PHC facilities. Participants observed that sometimes the PHC facilities might be closed for a particular function, such as when the healthcare providers needed to go into the communities to immunise children. However, this was linked to the lack of adequate staff to provide cover at these facilities.

"Most of the health facilities we have in remote areas now only have one person per health facility. Now we use to carry out these community activities, this ad hoc assignment, like immunisation or whatsoever. So, if that officer in charge leaves that clinic, when there is any case from the community, automatically for those four days you can't see him or her. So, they go straight to the secondary healthcare facility where they think they will definitely meet a personnel." CHW5. 
Other participants also pointed out that the secondary healthcare facilities are open 24 hours a day, in contrast to the irregular opening hours of the PHC facilities, which they perceived as also playing a role in patients bypassing the PHC facilities.
"When you go there [PHC facility] you won't meet them [PHC staff] at work... I want to say they don't have 24 hours service there, so when you go there at night you will not meet anybody. So, you have to come to the sec- ondary facility.” Doctor6.

\section{COST OF HEALTHCARE SERVICES}

It was remarked that services are likely cheaper at the PHC facilities due to the availability of free medications for some specific medical conditions. Nevertheless, it was pointed out that the irregular nature of the services provided by the PHC facilities cannot be depended on by the patients.

\begin{abstract}
"What if the medication is irregular? Just as I told you, when you need services, you can't get services when you need it. Of course, you have to go to another place, even if it is for free here [PHC facility]. But you can't find the health worker, so do you wait until he comes back? You can't wait. You have to move to where you can even pay money for you to secure your life." CHW5.
\end{abstract}

However, one of the doctors specifically noted that there is no significant difference between the service charge at the primary and secondary healthcare facilities. He emphasised that the increased cost of care experienced by patients at the secondary healthcare facilities is probably a result of investigations carried out at those facilities, which are not available at the PHC facilities.

"Well, the fees are the same thing. It is the same because cards here are being given for twenty naira. It's the same thing with primary health. Most of the investigations are done free, like malaria parasites, HIV screening... So, if you look at it that way, the fees might just be due to other investigations, like you now tend to talk of other higher investigations, where the patient have to pay." Doctor3.

Interestingly, it was also highlighted that patients who utilise the PHC facilities were perceived as people who do not have the financial capacity to use the secondary healthcare facilities.

\section{"People that will rather patronise them [PHC facility)] are people that might not have the financial capability." Doctor1.}

Reducing the cost of care for patients at the PHC facilities was suggested as a possible option to encourage the utilisation of the PHC facilities. One of the participants also suggested the need for adequate PHC facilities, and equitable distribution of these facilities within the community, to help decrease the bypass of the PHC facilities.

"The primary healthcare facilities in the first place have to be enough and properly placed, because we have this problem of placement of health facilities. Some of the placements are politically motivated. There are places that really need health facilities but you will discover that these buildings are not there... So, the health facility has to be properly sited." CHW5.

\section{LOCAL REGULATIONS AND POLICIES}

Participants (mainly doctors) also noted that the government have a vital role to play in ensuring that tangible policies are put in place to curtail the bypassing of the primary levels of care.
"I think the government has to play a role... until when there is solid policy on ground... stating, for anything that happens to you, you have to pass through the pri- mary health centre before you go to secondary health- care.” Doctor6.

A further suggestion was the need for the government to institute different financial charges between the secondary and PHC facilities, whereby patients who self-refer are made to pay more, with the aim of discouraging self-referral.
"Government can toe the line of action, where they have a basic standard cost for secondary healthcare, primary healthcare. So, people know even though you are going there... directly to the secondary health cen- tre, you know you are paying extra for it.” Doctor2.

\section{DISCUSSION}

Some of the reasons the healthcare providers suggested as being likely to influence the bypass of the PHC facilities included the preference by the patients to be attended to by medical doctors, and the lack of manpower at the PHC facilities. Interestingly, the medical knowledge of some of the staff rendering care at the PHC facilities was questioned, mainly by the participating doctors. These findings echoed the views of the patients from a previous study, who feared they could be given a wrong diagnosis by the healthcare providers within the PHC facilities. ${ }^{40}$ The understanding among the patients that the majority of healthcare providers at the primary level of care were either CHWs or nurses further amplified this concern, thus they voiced their preference to be attended to by doctors who are mainly only available at the higher levels of care. ${ }^{40} \mathrm{~A}$ similar finding was reported in the UK, whereby some patients felt the doctors at the emergency department had better knowledge than their general practitioners, which resulted in seeking care at the referral facility. ${ }^{41}$ Likewise, it's been found that the availability of staff alone does not ensure the delivery of quality care, as healthcare providers can lack the ability to make accurate diagnoses or to appropriately manage patients. ${ }^{36}$ In line with this concern, several studies ${ }^{42-45}$ have suggested reconsidering prioritising the service delivery of family physician specialists in Nigeria. Family physicians are trained doctors who have the expertise to provide care at the primary level, although this is not the case in Nigeria, given that the family physicians are rather linked with the referral level of care. ${ }^{42}$

Aside from the perception of the need to have a medical test that is unattainable at the PHC facilities, the healthcare providers also had a negative perception of the general environment of the PHC facilities, which they felt might likely 
influence the decision of the patients to bypass them. Likewise, in France and the UK the availability of resources, such as laboratory tests and radiography, were one of the advantages for patients presenting at the emergency department of a referral facility. ${ }^{34,41}$ In a study carried out in Saint Vincent and the Grenadines, it was not only the absence of attending doctors but also the absence of diagnostic facilities that further necessitated their participants to seek care at the referral facility. ${ }^{46}$ One of the themes that emerged from another study was the perceived need by patients to have a diagnosis. Thus, most of their interviewed patients had the perception that they would need an X-ray and so felt no need to see their General Practitioner (GP) because of the idea that they would still be sent to the emergency department. Therefore, they decided to self-refer. ${ }^{41}$ In an interview conducted among healthcare providers and patients, it was revealed that the availability of resources, such as laboratory tests and radiography, prompted patients to present at the emergency department. Furthermore, the availability of medication at the same place served as an attractive attribute for the patients to receive a complete package of care at a single place. ${ }^{34}$ In contrast, the healthcare providers (nurses, doctors, and paramedics) in a study conducted in the Republic of Ireland emphasised that service users' perceptions of their need for certain investigations is not always accurate. ${ }^{33}$

Healthcare providers in this current study revealed that presenting at the primary level of care was, for the patients, a waste of time and resources. This was based on the notion that patients were unlikely to get the care they needed despite spending their money and time at the primary level, thus were still likely to end up attending a higher level of care facility. The healthcare providers in this present study also felt that the relationship between patients and healthcare providers was a likely barrier in seeking care at a particular facility. Participants pointed out that the 'rapport' of some healthcare providers with their patients at the primary level of care was poor. Similarly, in a study from Tanzania, it was ascertained that the caretakers in their study felt that the healthcare providers within the PHC facilities lacked compassion for their sick children. They noted that the caretakers sometimes received ill-mannered responses from the healthcare providers - such as being yelled at which, in turn, occasionally influenced their decisions to avoid those facilities. ${ }^{31}$ Likewise, it's been reported that a critical aspect in the delivery of quality care is not only related to the knowledge and skills of the healthcare professionals but also the attitudes of the health professionals as perceived by the users. 36

In this study, the healthcare providers highlighted the socioeconomic status of patients as a potential factor for utilising either healthcare facility. However, despite this assumption, it is perceived that patients would still rather use the referral facilities because of the quality of care. In a study conducted in the US among patients of low socioeconomic status, they found that their participants viewed hospital care as more affordable than primary care because uninsured patients could not afford the fees for regular primary care visits and, therefore, relied on hospital charity when they fell ill. ${ }^{23}$ In contrast, the healthcare providers in the current study pointed out that the perceived higher cost of care at the secondary facilities could be due to the extended services provided at these facilities, such as the investigations carried out at the secondary level facilities. Notably, the Nigerian healthcare system is majorly funded through out-of-pocket payments from patients, which is likely to influence the choice of facility for healthcare. Therefore, due to the type of funding (such as insurance, general taxation, or out-of-pocket) for healthcare systems in different settings, this could impact on how patients use the healthcare services available to them.

The irregular nature of how the PHC facilities operate, such as the opening times and closure of the facilities for a period of time, was discussed as being a potential factor encouraging the use of higher levels of care. However, some of the healthcare providers remarked that this could be linked to the shortage of staff. They emphasised that some community activities, such as immunisations, occasionally warrant the PHC facilities to be closed. Similarly, in the Caribbean it was found that the limited scheduling of doctor-run clinics and the limited hours of the clinics motivated patients to self-refer to the accident and emergency department. ${ }^{46}$ For others, the inability to use their PHC facilities during regular opening hours due to conflicts with their work schedule prompted them to present at the referral facility. ${ }^{23,47}$ Additionally, some of the studies carried out in settings such as the US, Australia, and France showed that the inability to get appointments with their primary care providers, or the long waits to get appointments, were responsible for people seeking care at the referral facility. $23,34,47-49$

The healthcare providers suggested the need to institute financial charges for patients who self-refer directly to the referral facilities in order to deter them from doing so. In line with this finding, a study carried out in France also reported that the imposition of financial penalty on patients who inappropriately use referral facilities was suggested among the healthcare providers in their study. ${ }^{34}$ Nevertheless, any government policies in this regard will need to be critically evaluated, as well as being context specific.

Other suggestions proffered during the interviews with the healthcare providers as a potential means of addressing the patients bypassing the PHC facilities included the need to improve the healthcare provider-patient relationship, by ensuring good rapport and access to the healthcare providers when needed. The necessity to have adequate, trained, and qualified healthcare providers - with specific emphasis on medical doctors - stationed within the PHC facilities was also highlighted. Also, of note was the need for collaboration between the different levels of care, as current services appeared fragmented. There were also suggestions for facilities/equipment to be put in place at the primary level of care. These included renovation of the physical structures of the PHC facilities, availability of medications, and provision of equipment for investigations. Equitable distribution of PHC facilities was also proposed. In addition, a reduction in cost of providing healthcare services was advised, particularly as the Nigerian healthcare system is majorly funded by out-of-pocket payments.

The limitations of this study were that all the interviews of the current study were conducted during working hours 
on the premises of the health facilities, which might have impacted on the level of depth the participants were willing to talk about an issue in order to save time and complete their jobs for the day. Despite this limitation, the data that was collected reveals the complexities and the richness of the area of research. Aside from the fact that participating in this study was purely voluntary, the researcher's background as a healthcare provider appeared to have influenced the research process in a positive way, in terms of gaining access to the healthcare facilities and fostering the interview relationship with the healthcare providers. Accordingly, the concept of reflexivity in qualitative research acknowledges the input of the researchers in actively coconstructing the situation which they want to study. ${ }^{50} \mathrm{Be}-$ sides, the use of probing questions also helped to elicit specific answers from the participants.This study was also only conducted among the healthcare providers of the primary and secondary healthcare facilities; healthcare providers within the tertiary facilities were not included, thus their perceptions might have differed from the current findings.

\section{CONCLUSION}

The results from this study highlighted a number of contextual issues implicated in the bypassing of the PHC facilities, which will also need a contextual approach in order to address them. The findings suggest that factors such as the lack of manpower within the PHC facilities (especially the services of doctors), shortages and inequitable distribution of PHC facilities, lack of basic equipment within the PHC facilities, and out-of-pocket payment need to be given due consideration amongst other factors to ensure an improved healthcare referral system in Nigeria. In addition, the findings from this study have implications for planning, practice, and policy in service delivery aimed at curtailing the bypass of the PHC facilities. Future studies may aim at a quantitative examination of the identified factors in this study in order to enable generalisation.

Acknowledgements: This study was part of a $\mathrm{PhD}$ training; however, we would like to appreciate the research participants and the gatekeepers of the three secondary health- care facilities in Niger state that were used for this study.

Ethics approval and consent to participate: Ethics approval was granted for this study by the Institute of Health Research Ethical Committee (IHREC), University of Bedfordshire (Ref. number: IHREC464) and the National Health Research Ethical Committee (NHREC) in Nigeria (Ref. number: NHREC/01/01/2007). In addition, access to the general hospitals were granted by the Niger state hospital management board. Participation in this research was voluntary. Thus, participants were given adequate information about the research and signed consent was taken from the participants. Participants were also made aware that access to the transcripts and recordings will be limited to the research team. The recorded and transcribed data were password protected and stored with pseudonyms.

Consent for publication: All participants provided consent to publish anonymised data via the ethics approval.

Availability of data and materials: The datasets used and/ or analysed during the current study are available from the lead author on reasonable request.

\section{Funding: None}

Authorship contributions: FK was the lead author for this study, thus planning and writing of the protocol, data collection and analysis were carried out by FK. GR and BO also had substantial contribution to the development of all aspects of this study and the manuscript. All authors read and approved the final manuscript.

Competing interests: The authors completed the Unified Competing Interest form at www.icmje.org/coi_disclosure.pdf (available upon request from the corresponding author), and declare no conflicts of interest.

\section{Corresponding author:}

Bertha Ochieng, PhD

Professor of Integrated Health and Social Care

Faculty of Health \& Life Sciences, De Montfort University, Edith Murphy House, The Gateway. Leicester, LE1 9BH, UK.

Bertha.ochieng@dmu.ac.uk 


\section{REFERENCES}

1. World Health Organization (WHO). Management of health facilities: Referral systems. 2014. http://ww w.who.int/management/facility/referral/en/. Accessed January 12, 2020.

2. Marinker M. The referral system. Journal of the Royal College of General Practitioners. 1988;38:487-491.

3. Metz HC, ed. Nigeria: A Country Study. 1991. htt p://countrystudies.us/nigeria/50.htm. Accessed March 20,2015

4. Asuzu MC. The necessity for a health systems reform in Nigeria. J Com Med and PHC. 2004;16(1):1-3. doi:10.4314/jemphc.v16i1.32398

5. Osibogun A. Crisis and challenges in Nigeria health sector. Journal of community medicine and primary healthcare. J Com Med and PHC. 2004;16(2):1-7. doi:1 0.4314/icmphc.v16i2.32406

6. Scott-Emuakpor A. The Evolution of Health Care Systems in Nigeria: Which Way Forward in the Twenty-First Century. Nigerian Medical Journal. 2010;51:53-65.

7. National Primary Health Care Development Agency (NPHCDA). Minimum Standards for Primary Health Care in Nigeria.; 2013. http://nphcda.org/wp-content/ uploads/2013/08/Minimum-Standards-for-Primary- $\mathrm{H}$ ealth-Care-in-Nigeria.pdf. Accessed November 10, 2019.

8. Lambo E. Basic health services programme: The Nigerian experience. Vikalpa. 1982;7(2):119-128. do $\mathrm{i}: 10.1177 / 0256090919820205$

9. Makama JG, Iribhogbe P, Ameh EA. Overcrowding of accident \& emergency units: Is it a growing concern in Nigeria? Afr H Sci. 2015;15(2):457-465. do i:10.4314/ahs.v15i2.20

10. World Health Organization (WHO). Nigeria. 2020. https://www.who.int/countries/nga/en/. Accessed July 5, 2020.

11. World Bank. Maternal mortality ratio (modelled estimate, per 100,000 live births). 2020. https://dat a.worldbank.org/indicator/SH.STA.MMRT?end=201 7 \&start=2000\&view=chart. Accessed July 5, 2020.

12. World Bank. Out-of-pocket expenditure (\% of current health expenditure). 2020. https://data.world bank.org/indicator/SH.XPD.OOPC.CH.ZS. Accessed July 5,2020 .
13. Federal Ministry of Health, Nigeria. Strategies for Strengthening the Secondary Health Care (SHC) Delivery Service.; 2005. http://www.ilo.org/wcmsp5/g roups/public/---ed_protect/---protrav/---ilo_aids/doc uments/legaldocument/wcms 127574.pdf. Accessed January 12, 2020.

14. World Bank. Current health expenditure (\% of GDP) - Nigeria. 2020. https://data.worldbank.org/indi cator/SH.XPD.CHEX.GD.ZS?locations=NG. Accessed July 5, 2020.

15. World Health Organization (WHO). The Abuja Declaration: Ten Years On. 2011. http://www.who.int/ healthsystems/publications/Abuja10.pdf. Accessed January 5, 2020.

16. Lucas AO, Gilles HM. Short Textbook of Public Health Medicine in the Tropics. 4th ed. London: Arnold; 2013.

17. World Health Organization (WHO). Primary Health Care (PHC). WHO; 1978. http://www.unicef.or g/about/history/files/Alma_Ata_conference_1978_repo rt.pdf. Accessed October 18, 2019.

18. Okoli H, Obembe T, Osungbade K, Adeniji F, Adewole D. Self-referral patterns among federal civil servants in oyo state, South-Western Nigeria. Pan Afr Med J. 2017;26. doi:10.11604/pamj.2017.26.105.11483

19. Aguwa EN, Arinze-Onyia SU, Okeke T, Aniwada EC. Excessive and Inappropriate Utilization of a Tertiary Health Center in South-East Nigeria. TAF Preventive Medicine Bulletin. 2010;9:15-22.

20. Akande TM. Referral system in Nigeria: Study of a tertiary health facility. Annals of African Medicine. 2004;3:130-133.

21. Bryant JH, Richmond JB. Alma-Ata and Primary Health Care: An Evolving Story. 2008. https://parthea lth.3cdn.net/ea9818ff461c9fbd2c_89m6bh39v.pdf. Accessed June 20, 2015.

22. Aliu O, Sun G, Burke J, Chung KC, Davis MM. Specialist participation in healthcare delivery transformation: Influence of patient self-referral. $\mathrm{Am}$ J Manag Care. 2014;20:22-26.

23. Kangovi S, Barg FK, Carter T, Long JA, Shannon R, Grande D. Understanding why patients of Low socioeconomic status prefer hospitals over ambulatory care. Health Aff. 2013;32:1196-1203. do i:10.1377/hlthaff.2012.0825 
24. Abdi WO, Salgedo WB, Nebeb GT. Magnitude and Determinants of Self-Referral of Patients at a General Hospital, Western Ethiopia. SJCM. 2015;4(5):86-92. $\underline{\mathrm{d}}$ oi:10.11648/j.sjcm.20150405.12

25. Land L, Meredith N. An evaluation of the reasons why patients attend a hospital Emergency Department. International Emergency Nursing. 2013;21(1):35-41. doi:10.1016/j.ienj.2011.12.001

26. Rasoulynejad SA. Patient Views for Self-Referral to Specialists. Iranian Journal of Public Health. 2007;36:62-67.

27. Yaffee AQ, Whiteside LK, Oteng RA, et al. Bypassing proximal health care facilities for acute care: A survey of patients in a Ghanaian accident and emergency Centre. Trop Med Int Health. 2012;17:775-781. doi:10.1111/j.1365-3156.2012.0298 4.X

28. Kahabuka C, Kvåle G, Moland KM, Hinderaker SG. Why caretakers bypass primary health care facilities for child care - a case from rural Tanzania. BMC Health Serv Res. 2011;11:1-10. doi:10.1186/1472-696 3-11-315

29. Bianco A, Pileggi C, Angelillo IF. Non-urgent visits to a hospital emergency department in Italy. Public Health. 2003;117(4):250-255. doi:10.1016/s003 3-3506(03)00069-6

30. Kraaijvanger $N$, van Leeuwen $H$, Rijpsma $D$, Edwards M. Motives for self-referral to the emergency department: A systematic review of the literature. BMC Health Serv Res. 2016;16(1). doi:10.1186/s1291 3-016-1935-Z

31. Linden MCV, Lindeboom R, Linden NV, et al. Selfreferring patients at the emergency department: Appropriateness of ED use and motives for selfreferral. International Journal of Emergency Medicine. 2014;7:1-7.

32. Forrest CB, Weiner JP, Fowles J, et al. Self-referral in point-of-service health plans. J Am Med Assoc. 2001;285:2223-2231. doi:10.1001/jama.285.17.2223

33. Breen BM, McCann M. Healthcare providers attitudes and perceptions of 'inappropriate attendance' in the Emergency Department. International Emergency Nursing. 2013;21(3):180-185. doi:10.1016/j.ienj.2012.08.006

34. Durand A-C, Palazzolo S, Tanti-Hardouin N, Gerbeaux P, Sambuc R, Gentile S. Nonurgent patients in emergency departments: Rational or irresponsible consumers? Perceptions of professionals and patients. BMC Res Notes. 2012;5(1). doi:10.1186/175 6-0500-5-525
35. Masso M, Bezzina AJ, Siminski P, Middleton R, Eagar K. Why patients attend emergency departments for conditions potentially appropriate for primary care: Reasons given by patients and clinicians differ. Emergency Medicine Australasia. 2007;19:333-340.

36. World Health Organization, OECD, International Bank for Reconstruction and Development/The World Bank. Delivering Quality Health Services A Global Imperative for Universal Health Coverage. WHO; 2018. https://extranet.who.int/sph/docs/file/1654. Accessed April 20, 2020

37. Guest G, Namey E, Mitchell M. Collecting Qualitative Data: A Field Manual for Applied Research. London: SAGE Publications, Ltd; 2013. do i:10.4135/9781506374680

38. Lacey A, Luff D. Qualitative Data Analysis.; 2009. https://www.rds-yh.nihr.ac.uk/wp-content/uploads/2 013/05/9 Qualitative Data_Analysis_Revision_2009.p df. Accessed October 2, 2019.

39. Srivastava A, Thomson SB. Framework analysis: A qualitative methodology for applied policy research. Journal of Administration and Governance. 2009;4(2):72-79.

40. Koce F, Randhawa G, Ochieng B. Understanding healthcare self-referral in Nigeria from the service users' perspective: A qualitative study of Niger state. BMC Health Serv Res. 2019;19(1):209. doi:10.1186/s1 2913-019-4046-9

41. McGuigan T, Watson P. Non-urgent attendance at emergency departments. Emergency Nurse. 2010;18(6):34-38. doi:10.7748/en.18.6.34.s18

42. Ayodeji R, Abimbola S. How tertiary hospitals can strengthen primary health care in Nigeria. Niger Med J. 2014;55(6):519-520. doi:10.4103/0300-1652.144715

43. Mash R, Howe A, Olayemi O, et al. Reflections on family medicine and primary healthcare in subSaharan Africa. BMJ Glob Health. 2018;3(Suppl 3):e000662. doi:10.1136/bmigh-2017-000662

44. Yakubu K, Hoedebecke K, Pinho-Costa L, Popoola $\mathrm{O}$, Okoye I. A qualitative study of young Nigerian family physicians' views of their specialty. South African Family Practice. 2017;59(3):98-102.

45. Olalubi OA, Bello SI. Community-Based Strategies to Improve Primary Health Care (PHC) Services in Developing Countries. Case study of Nigeria. Journal of Primary Health Care and General Practice. 2020;4(1):1-6. 
46. Beache SK, Guell C. Non-urgent accident and emergency department use as a socially shared custom: A qualitative study. Emerg Med J. 2016;33:47-51. doi:10.1136/emermed-2014-204039

47. Grant R, Ramgoolam A, Betz R, Ruttner L, Green JJ. Challenges to accessing pediatric health Care in the Mississippi Delta: A survey of emergency department patients seeking nonemergency care. J Prim Care Community Health. 2010;1:152-157. doi:1 $\underline{0.1177 / 2150131910380727}$
48. Howard MS, Davis BA, Anderson C, Cherry D, Koller P, Shelton D. Patients' Perspective on Choosing the emergency Department for Nonurgent Medical Care: A Qualitative Study Exploring One Reason for Overcrowding. Journal of Emergency Nursing. 2005;31:429-435.

49. Koziol-McLain J, Price DW, Weiss B, Quinn AA, Honigman B. Seeking care for nonurgent medical conditions in the emergency department: Through the eyes of the patient. J Emerg Nurs. 2001;26:554-563. doi:10.1067/men.2000.110904

50. Flick U. An Introduction to Qualitative Research. 4th ed. London: Sage Publications; 2009. 